Western North American Naturalist 68(3), (C) 2008, pp. 311-318

\title{
THE LIFE CYCLES OF CLAASSENIA SABULOSA AND HESPEROPERLA PACIFICA (PLECOPTERA: PERLIDAE) IN TWO COLORADO STREAMS
}

\author{
Richard A. Thorp ${ }^{1,2}$, Boris C. Kondratieff 1 , Emily C. Thorp 3 , \\ Patrick B. Odenbeck ${ }^{4}$, and Michael J. Jarrett ${ }^{5}$
}

\begin{abstract}
We compared the life cycles of Claassenia sabulosa (Banks 1900) and Hesperoperla pacifica (Banks 1900) (Plecoptera: Perlidae) in allopatry and sympatry by studying 4 populations in 3 streams of the South Platte River Watershed, Colorado. We estimated 2-year life cycles for both C. sabulosa and H. pacifica in allopatry and sympatry. Evidence of egg diapausing and extended larval recruitment was noted for both species in allopatry and sympatry. There were no apparent differences in larval growth, larval recruitment, or adult emergence periodicity between allopatric and sympatric populations of C. sabulosa. In contrast, allopatric and sympatric H. pacifica populations exhibited differences in the timing of larval growth, larval recruitment, and adult emergence. We feel that the differences in the life cycles of these populations were likely related to water temperature because a substantial water temperature difference (degree days of 1761 and 2563) occurred between study reaches. In sympatry, H. pacifica adults began emerging 2 weeks earlier than C. sabulosa, when water temperature reached $9^{\circ} \mathrm{C}$. The emergence of $\mathrm{H}$. pacifica was synchronous and male biased. The emergence of C. sabulosa was protandrous and male biased and began when water temperature reached $17^{\circ} \mathrm{C}$. Claassenia sabulosa emergence was extended and lasted for 6 weeks during July and August. The abundance of $C$. sabulosa adults during this period corresponded closely to fluctuations in water temperature.
\end{abstract}

Key words: Plecoptera, Perlidae, stoneflies, life cycle emergence, streams, temperature, upper South Platte River.

Perlid stoneflies are conspicuous macroinvertebrate predators (Shapas and Hilsenhoff 1976, Fuller and Stewart 1979, Johnson 1981, Thorp et al. 2007) of benthic stream communities throughout North America (Wiggins and Mackay 1978). In many streams the spatial overlap of several perlid species is common (Sheldon 1985, 1999, Fuller and Hynes 1987, Fuller and DeStaffan 1988). Such coexistence may lead to competition between larvae for important resources such as food (Sheldon 1980, Peckarsky and Penton 1985) and possible resource partitioning (Sheldon 1980). Besides foraging behaviors, the mechanisms facilitating co-existence between species of this important family are poorly known. Studies comparing the life cycles of similar perlid species in allopatry versus sympatry have thus far been neglected (Stewart and Stark 2002).

The large perlid stoneflies Claassenia sabulosa (Banks 1900) and Hesperoperla pacifica (Banks 1900) are common in southern Rocky Mountain streams of North America (Richard- son and Gaufin 1971, Ward et al. 2002). Within these systems, spatial overlap (Fuller and Stewart 1979, DeWalt and Stewart 1995) and separation (McCutchen 2002) between these species is common. Claassenia sabulosa larvae are typically found in medium to large rivers up to $3000 \mathrm{~m}$ in elevation (Stewart and Stark 2002), while H. pacifica have a more plastic distribution and inhabit streams of various sizes (Kondratieff and Baumann 2002) up to $3500 \mathrm{~m}$ in elevation (Knight and Gaufin 1966). Both species are considered semivoltine (Hassage and Stewart 1990) and are thought to have life cycles lasting between 2 and 3 years (Sheldon 1979, Barton 1980, DeWalt and Stewart 1995). Claassenia sabulosa adults have been collected from July through early August (DeWalt et al. 1994, Alexander and Stewart 1996), whereas $H$. pacifica adults emerge during peak snowmelt runoff in June and often continue to emerge into July (Sheldon 1999).

In this study we addressed whether the life cycles (i.e., egg development, larval growth, and adult emergence) of C. sabulosa or $H$.

\footnotetext{
${ }^{1}$ Department of Bioagricultural Science and Pest Management, Colorado State University, Fort Collins, CO 80523.

${ }_{2}^{2}$ Present address: Wyoming Department of Environmental Quality, 122 W. 24th St., Herschler Building 4-W, Cheyenne, WY 82002. E-mail: rthorp@wyo.gov ${ }^{3}$ Department of Microbiology, Immunology, and Pathology, Colorado State University, Fort Collins, CO 80523.

${ }^{4}$ ENSR Environmental Consultants and Engineers, Fort Collins, CO 80525.

${ }^{5}$ Department of Food Science and Human Nutrition, Colorado State University, Fort Collins, CO 80523.
} 




Fig. 1. Map showing the locations of our 3 study reaches within the South Platte River Watershed, Colorado. Study reaches were located on the Big Thompson River (AHp and Sym) and St. Vrain Creek (ACs).

pacifica differ in streams where they occur in allopatry versus sympatry.

\section{Methods \\ Study Area}

We studied the life cycles of C. sabulosa and H. pacifica in allopatry and sympatry using 3 study reaches within the South Platte River Watershed, Colorado (Fig. 1). As described above, $H$. pacifica is relatively ubiquitous in Colorado mountain streams. Therefore, for the purpose of this study, we defined allopatry as an estimated $x 95 \%$ abundance of either species and sympatry as an approximately equal abundance of each. Using these definitions, we selected 3 study reaches, each approximately $50 \mathrm{~m}$ long: 1 along St. Vrain Creek and 2 along the Big Thompson River (Fig. 1). Our allopatric C. sabulosa study reach (hereafter ACs) was located along St. Vrain Creek within the eastern city limits of Lyons $\left(40.2179715^{\circ} \mathrm{N}, 105.2603104^{\circ} \mathrm{W}\right)$ at an elevation of $1653 \mathrm{~m}$; it had an approximate average annual streamflow of $3.84 \mathrm{~m}^{3} \cdot \mathrm{s}^{-1}(1994-2003$; USGS gaging station \#06725450). Our allopatric $H$. pacifica study reach (hereafter $\mathrm{AHp}$ ) was located along the upper Big Thompson
River, above Lake Estes $\left(40.3490154^{\circ} \mathrm{N}\right.$, $105.5699165^{\circ} \mathrm{W}$ ). The reach is at an elevation of $2439 \mathrm{~m}$, and average annual streamflow is approximately $1.4 \mathrm{~m}^{3} \cdot \mathrm{s}^{-1}(1996,2003-2004$; USGS gaging station \#402114105350101). Our sympatric study reach (hereafter Sym) was located along the lower Big Thompson River within the boundaries of the Viestenz-Smith Mountain Park $\left(40.4210606^{\circ} \mathrm{N}, 105.2705299^{\circ} \mathrm{W}\right)$. This reach is at an elevation of $1768 \mathrm{~m}$ and has an average annual streamflow of approximately $2 \mathrm{~m}^{3} \cdot \mathrm{s}^{-1}$ (1994-2003; USGS gaging station \#06741510). All 3 stream reaches were approximately $17 \mathrm{~m}$ wide and had open stream canopies. AHp contained larger, more-embedded cobbles and boulders within the streambed compared with ACs and Sym, making larval collections considerably more difficult. Riparian vegetation at Sym and ACs was mostly willows, cottonwoods, and various forbs and grasses, whereas cottonwoods were replaced by aspens, spruces, and pines at AHp.

\section{Field Survey}

We collected larvae of both species approximately every 2 weeks at our 3 study reaches between June 2004 and September 2005, except for the winter months of December through February, when ice and snow cover 


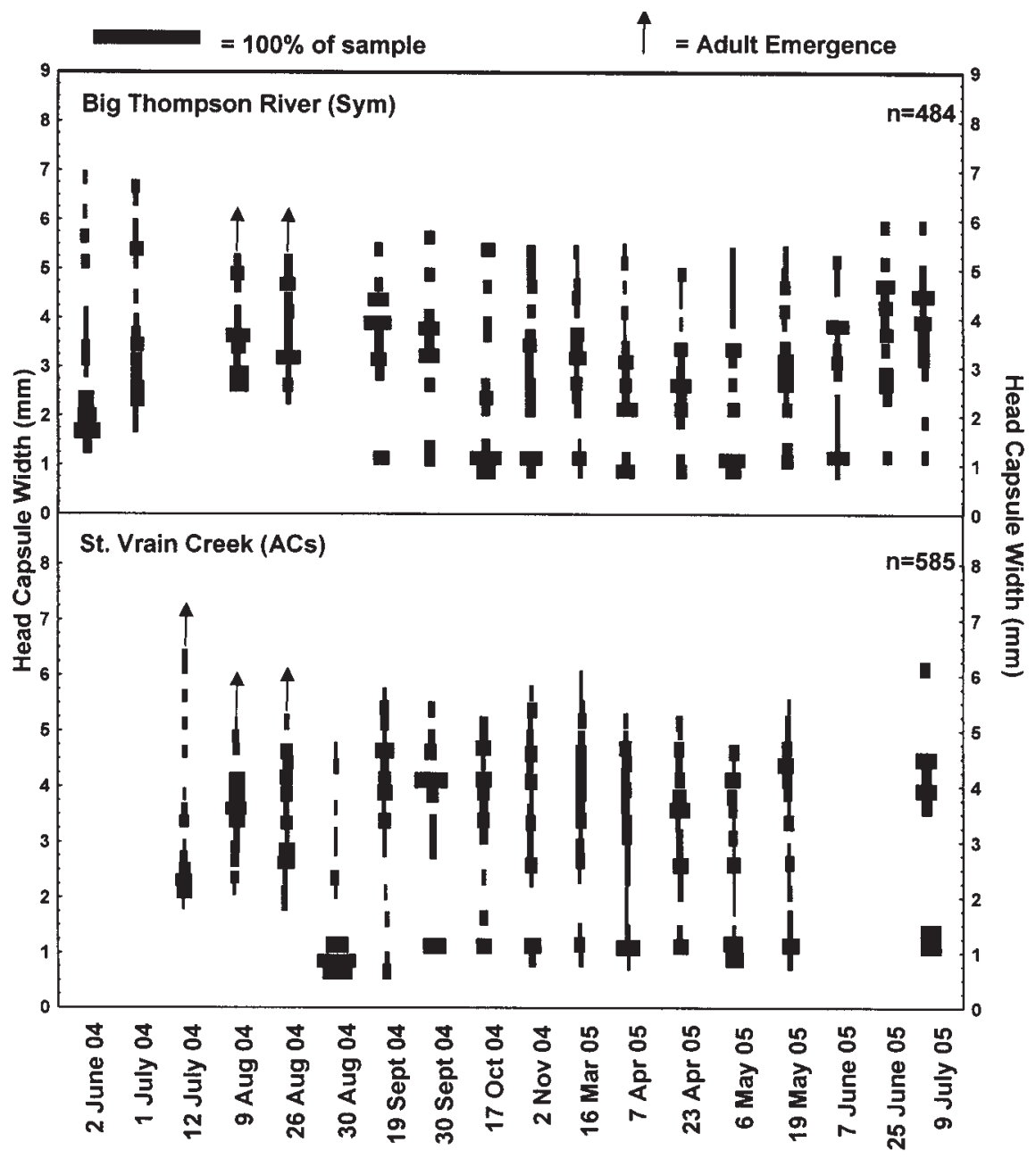

Fig. 2. Interocular distances of larval C. sabulosa collected from the Big Thompson River (Sym, $n=484$ ) and St. Vrain Creek (ACs, $n=585$ ) from June 2004 through July 2005. Head capsule width data from each sampling date were sorted into bins of $0.25 \mathrm{~mm}$; each black bar represents the percentage of the overall sample within a given bin. Black arrows represent sample dates in which adults were collected.

prohibited collections. As many larval stoneflies as possible were collected during sampling events, which typically lasted between 2 and 3 hours at each reach. Larval collections were made in riffle areas using a 500- $\mu$ m-mesh Dframe kicknet held vertically against the streambed. Streambed substrates immediately upstream of the net were disturbed in order to dislodge benthic macroinvertebrates. These animals were then washed via stream current into the downstream capture net. Debris within the net was placed in a white enamel pan filled with stream water and sorted on site using forceps. All stoneflies were immediately sorted from debris and preserved in $80 \%$ ethanol. We identified and counted C. sabulosa and H. pacifica larvae using a dissecting microscope, and measured interocular distances to the nearest $0.1 \mathrm{~mm}$ using an optical stage micrometer. During larval collections we also searched stream bank structures (e.g., under mineral substrata, and within grasses, woody debris, and trees) adjacent to the stream for stonefly adults and larval exuvia. We collected adults using forceps and immediately preserved them in $80 \%$ ethanol for later identification and enumeration. Water temperatures between our reaches were compared using data collected between July 2004 and September 2005 using remote temperature loggers placed within the streambed. 


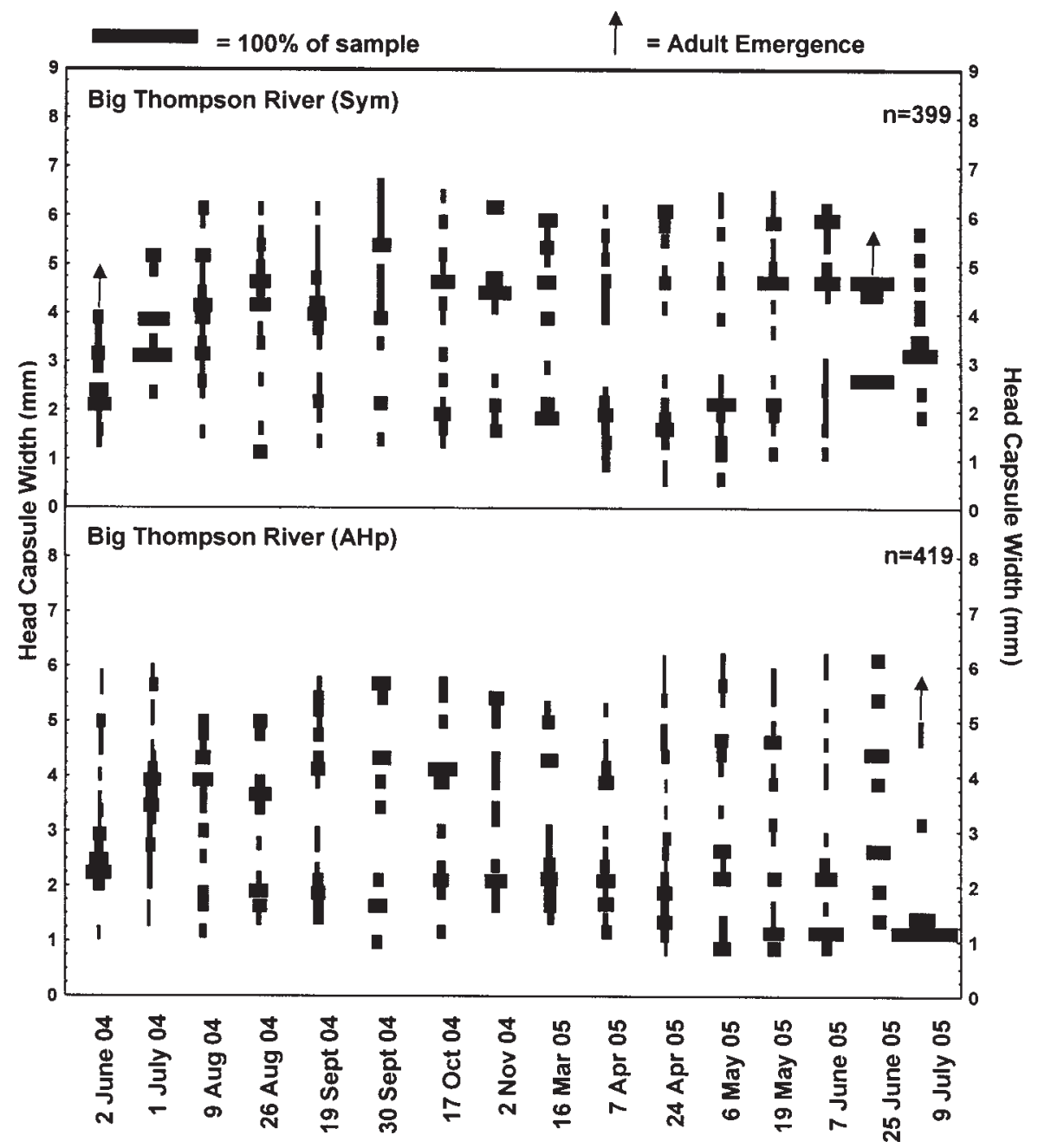

Fig. 3. Interocular distances of larval H. pacifica collected from the lower Big Thompson River (Sym, $n=399)$ and the upper Big Thompson River (AHp, $n=419$ ) from June 2004 through July 2005. Head capsule width data from each sampling date were sorted into bins of $0.25 \mathrm{~mm}$; each black bar represents the percentage of the overall sample within a given bin. Black arrows represent sample dates in which adults were collected.

Using an additional survey, we compared adult emergence periodicities and abundances of C. sabulosa and H. pacifica at Sym to stream water temperature. This survey consisted of an untimed search of various stream-bank structures within a $15-\mathrm{m}^{2}$ section of stream bank. These collections were made approximately every 4 days between early spring and late summer 2005 .

\section{RESUlts}

Our 3 stream reaches had substantially different water temperatures during the course of this study. AHp, ACs, and Sym had average annual degree days of 1761,2658 , and 2563 , respectively. Maximum $\left(15.7^{\circ} \mathrm{C}[\mathrm{AHp}]\right.$ to $18.1^{\circ} \mathrm{C}$ [Sym] $)$ and minimum $\left(-0.08^{\circ} \mathrm{C}[\mathrm{AHp}]\right.$ to $1.5^{\circ} \mathrm{C}$ [ACs]) temperature ranges also differed among our study reaches. AHp developed surface and anchor ice during November 2004, nearly a month before Sym and ACs. Ice and snow covered AHp by December and persisted until early March of the following year, whereas Sym and ACs maintained some ice-free areas throughout the winter.

Claassenia sabulosa and H. pacifica were the only perlid stoneflies collected during this 




Fig. 4. Number (left $y$-axis) of emerging male and female adult H. pacifica and C. sabulosa at Sym during summer 2005. Stream water temperatures (right $y$-axis) were plotted (black line) and compared to the emergence of each species and sex.

study. At ACs, C. sabulosa was more abundant, accounting for $97 \%$ of the perlid stoneflies collected. In all, we collected 585 C. sabulosa and $20 \mathrm{H}$. pacifica larvae from this reach between July 2004 and July 2005. Elevated streamflows during spring snowmelt runoff curtailed larval collections in June 2005. Interocular distances of C. sabulosa larvae at ACs ranged from 0.5 to $6.3 \mathrm{~mm}$ (Fig. 2). Adult emergence at this reach in 2004 was first observed during the middle of July and continued through the end of August (adult emergence in 2005 was not observed and likely occurred after our last sample was collected). Adults and larval exuvia were collected from stream-bank cobble surfaces and interstices, within approximately $1 \mathrm{~m}$ of the stream. Larval recruitment appears to have started during late August 2004 and continued through May 2005. Using our size-frequency and adult-emergence data (Fig. 2), we estimated that this population of $C$. sabulosa requires 2 years to develop.

Hesperoperla pacifica accounted for $100 \%$ of the perlid stoneflies collected from AHp. We collected $419 \mathrm{H}$. pacifica larvae from this study reach between June 2004 and July 2005, and larval interocular distances ranged from 0.6 to $6.4 \mathrm{~mm}$ (Fig. 3). Adult emergence was observed only during July 2005 . Larval exuvia were mostly collected at distances of more than $10 \mathrm{~m}$ from the stream, where they were found in aggregations on the trunks and limbs of trees. We did not collect adult H. pacifica at AHp in 2004, but our data suggest that adult emergence likely occurred during August and that larvae began recruiting into this population by late September. This fall recruitment period was relatively brief, and a 2 nd, more prolonged recruitment period appears to have occurred the following spring. These 2 larval recruitment periods suggest that eggs of this population diapause during winter. We estimated a 2-year life cycle for this population of H. pacifica (Fig. 3) using our size-frequency and adult-emergence data.

Claassenia sabulosa and H. pacifica accounted for $55 \%$ and $45 \%$ of the perlids collected from Sym, respectively. In all, we collected 484 C. sabulosa and 399 H. pacifica from this study reach. Claassenia sabulosa interocular distances ranged from 0.8 to $6.8 \mathrm{~mm}$, whereas H. pacifica interocular distances ranged from 0.6 to $6.6 \mathrm{~mm}$. Adult C. sabulosa were collected along this reach throughout August 2004 (Fig. 2) and from early July until late August 2005 (Fig. 4). Adult emergence of H. pacifica was 
observed during early June 2004 (Fig. 3), and during the middle of June 2005 (Fig. 4). The life cycles of C. sabulosa and H. pacifica observed at Sym appear to closely parallel those observed for each species at ACs and AHp. However, adult emergence and larval recruitment periods occurred substantially earlier (by approximately 1 month) for $H$. pacifica at Sym than for $H$. pacifica at AHp. We estimated a 2-year life cycle for both C. sabulosa and H. pacifica at Sym using our size-frequency and adult-emergence data.

The adult emergence periods of $C$. sabulosa and H. pacifica at Sym were separated by approximately 2 weeks in July (Fig. 4). Hesperoperla pacifica was protandrous and male biased, and males and females began a synchronous emergence when water temperature reached $9^{\circ} \mathrm{C}$. We collected 38 males between 9 June and 29 June compared with 19 females between 9 June and 25 June. Larval exuviae and adults were collected approximately equally from stream bank cobbles and vertical structures. Peak emergence periods for male and female $H$. pacifica closely overlapped and occurred on 17 June and 21 June, respectively, when water temperature was approximately $11^{\circ} \mathrm{C}$. The emergence of C. sabulosa was also protandrous and male biased. We collected 58 males between 19 July, when water temperature reached $17^{\circ} \mathrm{C}$, and 31 August; we also collected 3 females between 31 July, when water temperature was $18^{\circ} \mathrm{C}$, and 9 August (Fig. 4). Larval exuviae and adults were collected from stream bank cobbles (Fig. 4) within $1 \mathrm{~m}$ of the stream. The emergence of male C. sabulosa fluctuated for nearly 6 weeks, peaking on 23 August. This pattern apparently paralleled fluctuations in water temperature (Fig. 4). Female C. sabulosa adult emergence peaked on 9 August at a temperature of $17^{\circ} \mathrm{C}$. Unfortunately, our temperature logger was removed from the stream prior to the end of this study.

\section{Discussion}

Our data suggest a semivoltine life cycle for both C. sabulosa populations in our study, thus corroborating the results of previous studies of this stonefly in southern Colorado (Fuller and Stewart 1977, Allan 1982, Hassage and Stewart 1990) and Alberta (Barton 1980). In these studies the life cycle of $C$. sabulosa was reported as lasting between 2 and 3 years;
DeWalt and Stewart (1995) estimated a 3-year life cycle for a population from a southern Colorado River. We suggest that the data presented here describe a 2-year life cycle for this species. The timing of larval growth, egg diapause, larval recruitment, and adult emergence periods was remarkably similar for both populations studied, which may be due to comparable water temperatures between ACs and Sym. Larval recruitment occurred during both late summer to early fall and early spring to summer. Small larvae (interocular distance $\leq 1$ $\mathrm{mm})$ were also collected during November and March, which may indicate that egg hatching and larval recruitment continued during winter, as suggested by Barton (1980). However, we believe that summer-fall C. sabulosa larval recruits and eggs likely diapause during winter months, as has been reported for other large perlid species (Vaught and Stewart 1974).

The protandrous and heavily male-biased adult emergence of C. sabulosa at Sym was consistent with reports describing other Colorado populations (DeWalt and Stewart 1995, Alexander and Stewart 1996). This accelerated emergence behavior exhibited by males has been described by Alexander and Stewart (1996) as a reproductive strategy in which some males emerge early, wait, and ambush lateremerging females as they leave the water. Apparently this strategy can be so effective that some females are mated before they have finished molting their larval skins (Alexander and Stewart 1996). The behavior described above may explain why males in the current study began emerging at Sym when water temperatures reached $17^{\circ} \mathrm{C}$, whereas females were not collected until temperatures reached $18^{\circ} \mathrm{C}$.

To our knowledge this study represents the 1st report of the life cycle of $H$. pacifica using data from more than 1 sampling location and date. Our larval size-frequency and adultemergence data describe a semivoltine life cycle for this stonefly, thus supporting previous studies of populations occurring in a southern Colorado river (Fuller and Stewart 1977), a Montana creek (Sheldon 1980), and an Idaho stream (Robinson et. al. 1992). Larval recruitment in our 2 study populations began in late summer, and these recruits appeared to continue growing during winter (Fig. 3). A 2nd larval recruitment period occurred the following spring for both populations, ending just prior to adult emergence. Sheldon (1980) 
reported a 3-year life cycle for this species, but this conclusion was supported using data from only a single sampling date. Further, Sheldon (1980) suggests that the life cycle of this species is difficult to understand because of sexual dimorphism in the larvae. We believe that there is strong evidence in the current study suggesting that $H$. pacifica utilizes egg diapause and an extended larval recruitment during its life cycle and that these traits complicate life-cycle studies with small sample sizes. We interpret our data and those of Sheldon (1980) as describing a 2-year life cycle for H. pacifica.

The adult emergence of $H$. pacifica at Sym was synchronous and male biased, with both males and females emerging within a 16-day period in June. Emergence of male and female $H$. pacifica began when water temperature reached $11^{\circ} \mathrm{C}$, and peak emergence occurred when water temperatures reached $14^{\circ} \mathrm{C}$ for males and $11^{\circ} \mathrm{C}$ for females. Sheldon (1999) reported that emerging $H$. pacifica individuals from a Montana creek population were synchronous and highly female biased, and that adult emergence lasted for 13 days in June. Adults of this Montana population showed a relatively consistent and nonpeaked emergence pattern.

Water temperature has been identified as important in the emergence patterns of other stoneflies (Gregory et. al. 2000). Similarly, our data suggest that water temperature may be important for C. sabulosa and H. pacifica as an environmental cue. We believe that the large annual temperature differences between AHp and Sym likely contributed to the delayed adult emergence of H. pacifica at the cooler AHp. Also, the annual degree days and timing of $C$. sabulosa emergence at AHp and Sym were remarkably similar.

Although the life cycles of these species are very similar, discrete differences in adult emergence timing and duration, in tandem with egg diapause and extended larval recruitment, may facilitate their coexistence. Future life-cycle research with these species should be directed at determining the water temperatures that prompt embryogenesis and egg diapause to establish relevant developmental thresholds (Frutiger 1996, Zwick 1996a, 1996b). To our knowledge, the only such study using these species in a controlled laboratory culture was unsuccessful (DeWalt and Stewart 1995).

\section{ACKNOWLEDGMENTS}

This manuscript is from a thesis submitted to the academic faculty of Colorado State University in partial fulfillment of the degree of Master of Science. We thank the city of Loveland, Colorado, and the YMCA of the Rockies, Estes Park, Colorado, for granting access to our study reaches. We also thank Drs. William Clements, Ruth Hufbauer, and Nicole Vieira for their suggestions and assistance in conducting this research and preparing the resulting manuscript. We extend thanks to Ryan Fitzpatrick for his field assistance and Travis Schmidt for making the map.

\section{Literature Cited}

AleXander, K.D., AND K.W. STEWART. 1996. Descriptions and theoretical considerations of mate finding and other adult behavior in a Colorado population of Claassenia sabulosa (Plecoptera: Perlidae). Annals of the Entomological Society of America 89:290-295.

ALLAN, J.D. 1982. Feeding habits and prey consumption of three setipalpian stoneflies (Plecoptera) in a mountain stream. Ecology 63:26-34.

BAnKs, N. 1900. New genera and species of Nearctic neuropteroid insects. Transactions of the American Entomological Society 26:239-259

BARTON, D.R. 1980. Observations on the life histories and biology of Ephemeroptera and Plecoptera in northeastern Alberta. Aquatic Insects 2:97-111.

Dewalt, R.E., AND K.W. STEWART. 1995. Life histories of stoneflies (Plecoptera) in the Rio Conejos of southern Colorado. Great Basin Naturalist 55:1-18.

Dewalt, R.E., K.W. Stewart, S.R. Moulton, II, and J.H. KenNEDy. 1994. Summer emergence of mayflies, stoneflies and caddisflies from a Colorado mountain stream. Southwestern Naturalist 39:249-256.

Frutiger, A. 1996. Embryogenesis of Dinocras cephalotes, Perla grandis and $P$. marginata (Plecoptera: Perlidae) in different temperature regimes. Freshwater Biology 36:497-508.

Fuller, R.L., and P.A. Destaffan. 1988. A laboratory study of the vulnerability of prey to predation by three aquatic insects. Canadian Journal of Zoology 66:875-878.

Fuller, R.L., AND H.B.N. Hynes. 1987. Feeding ecology of three predacious aquatic insects and two fish in a riffle of the Speed River, Ontario. Hydrobiologia 150:243-255.

Fuller, R.L., AND K.W. Stewart. 1977. The food habits of stoneflies (Plecoptera) in the upper Gunnison River, Colorado. Environmental Entomology 6:293302.

. 1979. Stonefly (Plecoptera) food habits and prey preference in the Dolores River, Colorado. American Midland Naturalist 101:170-181.

Gregory, J.S., S.S. Beesley, and R.W. VAN Kirk. 2000. Effect of springtime temperature on the time of emergence and size of Pteronarcys californica in the Henry's Fork catchment, Idaho, U.S.A. Freshwater Biology 45:75-83. 
Hassage, R.L., and K.W. Stewart. 1990. Growth and voltinism of five stonefly species in a New Mexico mountain stream. Southwestern Naturalist 35:130 134.

Johnson, J.H. 1981. Food habits and dietary overlap of perlid stoneflies (Plecoptera) in a tributary of Lake Ontario. Canadian Journal of Zoology 59:2030-2037.

Knight, A.W., AND A.R. Gaufin. 1966. Altitudinal distribution of stoneflies (Plecoptera) in a Rocky Mountain drainage system. Journal of the Kansas Entomological Society 39:668-675.

Kondratieff, B.C., And R.W. Baumann. 2002. A review of the stoneflies of Colorado with description of a new species of Capnia (Plecoptera: Capniidae). Transactions of the American Entomological Society 128:285-401.

McCutchen, N.A. 2002. The response of stonefly (Plecoptera) nymphs to seasonal increases in predation risk. Canadian Journal of Zoology 80:967-972.

Peckarsky, B.L., AND M.A. Penton. 1985. Is predacious stonefly behavior affected by competition? Ecology 66:1718-1728.

Richardson, J.W., And A.R. Gaufin. 1971. Food habits of some western stonefly nymphs. Transactions of the American Entomological Society 97:91-121.

Robinson, C.T., L.M. ReEd, and G.W. Minshall. 1992. Influence of flow regime on the life-history, production, and genetic structure of Baetis tricaudatus (Ephemeroptera) and Hesperoperla pacifica (Plecoptera). Journal of the North American Benthological Society 11:278-289.

Shapas, T.J., AND W.L. HilsenhofF. 1976. Feeding habits of Wisconsin's predominant lotic Plecoptera, Ephemeroptera, and Trichoptera. Great Lakes Entomologist 9:175-188.

Sheldon, A.L. 1979. Stonefly (Plecoptera) records from the basin ranges of Nevada and Utah. Great Basin Naturalist 39:289-292.

1980. Coexistence of perlid stoneflies (Plecoptera): predictions from multivariate morphometrics. Hydrobiologia 71:99-105.
1985. Perlid stoneflies (Plecoptera) in an Appalacian drainage: a multivariate approach to mapping stream communities. American Midland Naturalist 113:334-342.

1999. Emergence patterns of large stoneflies (Plecoptera: Pteronarcys, Calineuria, Hesperoperla) in a Montana River. Great Basin Naturalist 59:169-174.

SteWART, K.W., AND B.P. StaRK. 2002. Nymphs of North American stonefly genera (Plecoptera). Caddis Press, Columbus, $\mathrm{OH}$

Thorp, R.A., J.B. Monroe, E.C. Thorp, T.A. Wellnitz, AND N.L. PofF. 2007. Food and habitat relationships of Claassenia sabulosa (Plecoptera: Perlidae) in the upper Colorado River, Colorado. Western North American Naturalist 67:57-62.

Vaught, G.L., and K.W. Stewart. 1974. The life history and ecology of the stonefly Neoperla clymene (Newman) (Plecoptera: Perlidae). Annals of the Entomological Society of America 67:167-178.

Ward, J.V., B.C. KondratiefF, AND R.E. Zuellig. 2002. An illustrated guide to the mountain stream insects of Colorado. 2nd edition. University Press of Colorado, Boulder.

Wiggins, G.B., AND R.J. MacKay. 1978. Some relationships between systematics and trophic ecology in nearctic aquatic insects, with special reference to Trichoptera. Ecology 59:1211-1220.

ZwICK, P. 1996a. Capacity of discontinuous egg development and its importance for the geographic distribution of the warm water stenotherm Dinocras cephalotes (Insecta: Plecoptera: Perlidae). International Journal of Limnology 32:147-160.

. 1996b. Variable egg development of Dinocras spp. (Plecoptera, Perlidae) and the stonefly seed bank theory. Freshwater Biology 35:81-100.

Received 14 November 2007 Accepted 8 February 2008 